\title{
Risk factors for acute coronary events in patients with rheumatoid arthritis

\author{
Abdulsalam Noorwali ${ }^{\mathrm{a}}$, Narges Omran ${ }^{\mathrm{b}}$, Samah H. Elmedany ${ }^{\mathrm{c}}$,
} Amal M. El-Barbary ${ }^{\mathrm{C}}$
}

\author{
aDepartment of Internal Medicine, Umm Alqura \\ University, bepartment of Internal Medicine, \\ Alnoor General Hospital, Makkah, Saudi \\ Arabia, ${ }^{\mathrm{C}}$ Department of Rheumatology and \\ Rehabilitation, Faculty of Medicine, Tanta \\ University, Tanta, Egypt \\ Correspondence to Amal M. El-Barbary, MD, \\ Department of Rheumatology and \\ Rehabilitation, Faculty of Medicine, Tanta \\ University, El-Geish Street, Tanta, Gharbia, \\ 31511, Egypt; Tel: 0403352236 \\ e-mail: ml_barbary@yahoo.com \\ Received 14 March 2017 \\ Accepted 21 May 2017
}

Egyptian Rheumatology \& Rehabilitation 2017, 44:164-171

\begin{abstract}
Objectives
The aim of this study was to assess the role of disease activity, line of treatment, and carotid atherosclerosis in the risk for acute coronary syndrome (ACS) in rheumatoid arthritis (RA) patients.

Patients and methods

In this prospective study, we ascertained ACS on 124 patients with RA. Disease activity score 28 was used for the assessment of RA activity. Insulin resistance was evaluated using homeostasis model assessment-insulin resistance. Carotid atherosclerosis was measured using high-resolution ultrasound. We used Cox's proportional hazards models to estimate the association between ACS and atherosclerosis, cardiovascular (CV) risk factors, and RA line of treatment.

Results

Among the 124 RA patients without a history of previous ACS, 16 incident ACS events occurred over 30 months. Old age, long RA disease duration, high BMI, and 10-year cardiovascular disease risk were associated with an increased risk for ACS. High mean disease activity score 28, rheumatoid factor, and anticitrullinated peptide antibodies (ACPA) levels were significantly associated with ACS risk. Treatment with disease-modifying antirheumatic drugs or biological disease-modifying antirheumatic drugs (DMARDs) did not alter the ACS risk. Logistic regression analysis showed that carotid plaques were a good predictor for ACS in RA patients. Conclusion

The main finding of this study was a general tendency toward an association of disease activity, rheumatoid factor, and ACPA with the risk for ACS. In addition, subclinical atherosclerosis detected by means of carotid intima-media thickness and the presence of carotid plaques were good predictors for RA patients with ACS. Treatment with any DMARD or biologic DMARDs was not linked to an altered risk for ACS.
\end{abstract}

\section{Keywords:}

acute coronary syndrome, atherosclerosis, rheumatoid arthritis

Egypt Rheumatol Rehabil 44:164-171

(c) 2017 Egyptian Society for Rheumatology and Rehabilitation

$1110-161 \mathrm{X}$

\section{Introduction}

Cardiovascular disease (CVD) is considered the chief cause of death in rheumatoid arthritis (RA) patients. RA increases the risk for cardiovascular $(\mathrm{CV})$ mortality by up to $50 \%$ when compared with general population [1-3]. Traditional CV risk factors (hypertension, smoking, and diabetes mellitus) failed to explain the increased risk for mortality in RA [4].

Systemic inflammation associated with RA appears to be a key factor of increased CV risk [1]. Chronic inflammatory state in RA is related to accelerated atherosclerosis, exacerbating adverse changes in both proven and novel $\mathrm{CV}$ risk factors $[5,6]$.

Atherosclerosis of the carotid vasculature has a direct link with high CVD rates [7]. Measurement of the intima-media thickness (IMT) of the carotid artery is a noninvasive useful index for detecting preclinical atherosclerosis and predictor of coronary artery diseases [8].

Furthermore, histological evidence of inflammation and plaque instability in the coronary arteries of patients with RA was detected in a postmortem series compared with non-RA controls [9]. This supports the theory that the mechanisms responsible for $\mathrm{CV}$ events in RA may vary from those in the general population.

The aim of this study was to assess the role of clinical and laboratory measures of disease activity, line of treatment, multiple $\mathrm{CV}$ risk factors, and carotid

This is an open access article distributed under the terms of the Creative Commons Attribution-NonCommercial-ShareAlike 3.0 License, which allows others to remix, tweak, and build upon the work noncommercially, as long as the author is credited and the new creations are licensed under the identical terms. 
atherosclerosis on the risk for acute coronary syndrome (ACS) in a relatively large cohort of RA patients.

\section{Patients and methods \\ Study design}

Between 1 January 2014 and 30 June 2016, the present cross-sectional study was conducted on 124 RA patients who fulfilled the 2010 RA classification criteria [10]. The sample size for the present study originated from a group of 230 consecutive RA patients (28 patients were excluded due to overlap with other rheumatic diseases, 32 patients were excluded because of a history of ischemic heart disease before the diagnosis of RA, 40 patients were excluded due to severe comorbid condition, and six patients were unwilling to participate in the study).

The patients were recruited from the rheumatology outpatient clinic and rheumatology Inpatient Department of Alnoor Specialist Hospital, a tertiary care teaching institute in Makkah, Saudi Arabia. Patients with the following conditions were excluded from the study: (i) age under 18 years; (ii) RA overlap with other rheumatic diseases; (iii) individuals with a history of ischemic heart disease before the diagnosis of RA; (iv) cases of ACS that began before the baseline visit were not counted in this study; (v) severe comorbid cases such as patients with end-stage renal failure, respiratory failure, and liver failure, which is likely to compromise survival or study participation; and (vi) unwillingness to cooperate with study procedures, or other inabilities.

Approval was obtained from the Local Research Ethics Committee of Alnoor Specialist Hospital, and written informed consent was obtained from each participant $(\mathrm{N}: 11237)$.

\section{Clinical assessment}

Patients were subjected to the following procedures: full medical history; thorough clinical examination including general and systemic (especially blood pressure measurement and BMI calculation) and information on all systemic treatments with antiplatelet usage (asprin), lipid-lowering medication (statin), disease-modifying antirheumatic drugs (DMARDs), glucocorticoid treatment, and its dose and biological DMARDs.

RA disease activity was assessed using the disease activity score 28 (DAS28) [11] and classified as low, moderate, or high disease activity according to the European League against Rheumatism definition, with low disease activity defined as DAS28 less than or equal to 3.2, moderate defined as DAS28 between 3.2 and less than or equal to 5.1 , and high defined as DAS28 greater than 5.1. Remission is defined as DAS28 less than 2.6 [12]. Health Assessment Questionnaire results were also collected [13].

Medical chart data including all visits at rheumatology clinics or cardiology clinic from the time of RA diagnosis to the end of the study were collected. Patients were evaluated until completion of the study, or the initial occurrence of ACS, the one that occurred first. In the event of multiple occurrences of ACS, only the first was counted.

ACS outcome was defined as the first episode of ACS and/or intervention for ACS registered (myocardial infarction, unstable angina, cardiac arrest, or death with ischemic heart disease listed as the first or first underlying cause of death on the death certificate) after RA diagnosis until the end of the study. Medical charts were retrieved to ensure that the diagnostic criteria for ACS, as defined by the Joint European Society of Cardiology/American College of Cardiology Committee [14], were fulfilled. Conventional CVD risk factors such as age, sex, smoking status, systolic blood pressure, total cholesterol, high-density lipoprotein cholesterol, and the Systematic Coronary Evaluation Score (SCORE) [15] were calculated to determine the 10-year risk for fatal CVD.

\section{Laboratory evaluation}

The following laboratory investigations were carried out: complete blood count, fasting venous plasma glucose, fasting serum insulin level (enzyme-linked immunosorbent assay method), serum lipid profile, rheumatoid factor (RF), and anticyclic citrullinated protein antibody. Insulin resistance (IR), which is the main outcome of the metabolic syndrome, was evaluated using the homeostasis model assessment (HOMA) (calculator available from www. OCDEM. ox.ac.uk), which is based on fasting plasma glucose and serum insulin concentrations [16]. Values were considered abnormal when HOMA-IR was more than 2 [17].

\section{Carotid ultrasound}

After a baseline evaluation at the recruitment site, we invited all patients for an additional visit to undergo a high-resolution B-mode carotid ultrasound evaluation; Mylab 70 Esaote (Genoa, Italy) equipped with a $7-12 \mathrm{MHz}$ linear transducer and the automated software-guided technique radio frequency-quality IMT in real-time (Esaote, Maastricht, the Netherlands) was used. 
The patients were placed in supine position with the chin extended, turning the head away from the side being examined. Measurements were made bilaterally at the carotid bulb, at $1 \mathrm{~cm}$ distal to common carotid artery far wall proximal to the bulb and in the proximal most portion of the internal carotid artery near its origin. The mean of the six readings so obtained was used to calculate the carotid intima-media thickness (CIMT) [18]. A cutoff value of $0.72 \mathrm{~mm}$ was taken for IMT; patients who had IMT above this value were considered to have atherosclerosis [19]. Carotid artery plaques were identified bilaterally as recommended in the Mannheim consensus - that is, when a focal structure that encroaches into the arterial lumen of at least $0.5 \mathrm{~mm}$ or $50 \%$ of the surrounding IMT value or demonstrates a thickness of greater than $1.5 \mathrm{~mm}$ as measured from the media-adventitia interface of the intima-lumen interface [20].

\section{Statistical analysis}

The collected data were coded, tabulated, and statistically analyzed using statistical package for social science SPSS version 17.0 (SPSS, Chicago, IL, USA). Quantitative variables were described as mean and SD. Qualitative variables were described as number and percentage. The unpaired $t$-test was used to compare two groups as regards quantitative variables. The $\chi^{2}$-test was used to compare qualitative variables between groups. The oneway analysis of variance test was used to compare more than two groups. The Spearman correlation test was used to rank different variables against each other positively or inversely. Logistic regression analysis was used to discover the effect of qualitative parameters in another parameter. A $P$-value less than or equal to 0.05 was considered statistically significant. Cox proportional hazard models were used to evaluate associations between risk factors and development of ACS. Associations were expressed in the form of hazard ratios, and 95\% confidence intervals represented the uncertainty of the estimation. The hazard ratio was interpreted as a multiplier of the risk for ACS, corresponding to a $1-\mathrm{U}$ increase in the predictor.

\section{Results}

One hundred and twenty-four RA patients were included in this study [110 (88.7\%) female and 14 (11.3\%) male]. Patients were subdivided according to the presence or absence of ACS into two groups (Table 1). Patients with ACS were in their fifth decade of life (mean \pm SD: $58.31 \pm 12.16)$ years with a significant difference between them and patients without ACS as regards the age (Table 1). There was no association between hypertension, diabetes mellitus, or smoking and ACS. Patients with high BMI were significantly associated with a risk for ACS $(P=0.025)$. RA patients with ACS were significantly associated with the 10-year CVD risk $(P<0.05)$. The mean RA disease duration among patients with ACS was 10.11 years with a significant difference between them and patients without ACS.

The high DAS28 was associated with an increased risk for ACS. Among the other DAS28 components (number of tender joints and number of swollen joints), there were generally negative associations except for patient global health assessment, which was significantly associated with ACS $(P=0.05)$. Almost $60 \%$ of the patients with ACS (62.5\%) had moderate DAS28 score (3.2-5.1); $12.5 \%$ had severe disease activity. Only four (12\%) patients had mild disease activity.

On comparison of serum lipid profile among patients with and those without ACS, there was no significant difference in the mean serum total cholesterol, triglycerides, low-density lipoprotein, and highdensity lipoprotein levels between the two groups. In the present study, serum insulin levels and IR determined using the HOMA-IR were found to be significantly higher in patients in the ACS group compared with the other group.

Univariate analysis demonstrated a statistically significantly increased risk for ACS in patients with high $\mathrm{C}$-reactive protein $(\mathrm{CRP})$, positive $\mathrm{RF}$, and high level of anticyclic citrullinated protein antibody.

The mean IMT at various points of measurement and the mean of the six-readings, CIMT, are shown in Table 1. RA patients with ACS had a higher mean CIMT compared with RA patients without ACS $(P=0.001)$. Carotid plaque was found more frequently among the cases with ACS compared with cases without ACS $(P=0.034)$.

Figure 1 showed that for a cutoff value of CIMT greater than or equal to $0.72 \mathrm{~mm}$, the sensitivity and specificity were 75.0 and $70.4 \%$, respectively, with an accuracy of $76.9 \%$. In addition, logistic regression analysis showed that plaques were a strong predictor for ACS in RA patients (the sensitivity and specificity were 62.5 and $84.259 \%$, respectively, with an accuracy of $81.452 \%)$.

Table 2 shows the recorded characteristics that were independently significantly related to ACS patients in a multivariable logistic regression model. Of the 14 
Table 1 Comparison between the two groups of rheumatoid arthritis patients as regards demographic, cardiovascular risk, clinical, laboratory, and radiological parameters

\begin{tabular}{|c|c|c|c|c|}
\hline & Patients without ACS $(n=108)$ & Patients with ACS $(n=16)$ & $P$-value & Odd $(95 \% \mathrm{Cl})$ \\
\hline \multicolumn{5}{|l|}{ Demographics } \\
\hline Age (years) & $48.44 \pm 12.83$ & $58.31 \pm 12.16$ & $0.005^{\star}$ & $1.072(1.019-1.127)$ \\
\hline \multicolumn{5}{|l|}{ Sex } \\
\hline Male & $11(10.19)$ & $3(18.75)$ & 0.344 & $0.491(0.121-1.996)$ \\
\hline Female & $97(89.81)$ & $13(81.25)$ & & \\
\hline \multicolumn{5}{|l|}{ CVR factor } \\
\hline Hypertensive $^{a}$ & $53(49.07)$ & $10(62.50)$ & 0.320 & $1.730(0.587-5.094)$ \\
\hline Diabetes mellitus & $31(28.70)$ & $6(37.50)$ & 0.481 & $1.490(0.499-4.453)$ \\
\hline BMI $\left(\mathrm{kg} / \mathrm{m}^{2}\right)$ & $28.194 \pm 6.604$ & $30.507 \pm 5.154$ & $0.025^{*}$ & $1.11(1.013-1.219)$ \\
\hline Current smoker & $9(8.33)$ & $3(18.75)$ & 0.201 & $2.54(0.608-10.595)$ \\
\hline 10 years CVR & $2.73 \pm 3.85$ & $6.88 \pm 7.36$ & $0.042^{*}$ & $1.146(1.046-1.255)$ \\
\hline \multicolumn{5}{|l|}{ Disease status } \\
\hline Duration of RA (years) & $5.462 \pm 4.767$ & $10.113 \pm 7.114$ & $<0.001^{\star \star}$ & $1.253(1.107-1.418)$ \\
\hline DAS28 & $3.343 \pm 1.193$ & $3.796 \pm 1.059$ & $0.028^{*}$ & $1.285(0.801-2.062)$ \\
\hline \multicolumn{5}{|l|}{ EULAR disease activity score } \\
\hline$\leq 3.1$ (low) & $40(37.04)$ & $4(25)$ & 0.290 & $1.602(0.669-3.836)$ \\
\hline 3.2-5.1 (moderate) & $60(55.56)$ & $10(62.50)$ & & \\
\hline$\geq 5.2$ (high) & $8(7.41)$ & $2(12.50)$ & & \\
\hline Disease disability index & $0.93 \pm 1.14$ & $1.06 \pm 0.68$ & 0.505 & $1.102(0.732-1.659)$ \\
\hline \multicolumn{5}{|l|}{ Laboratory values } \\
\hline Total cholesterol (mg/dl) & $187.66 \pm 42.25$ & $184.19 \pm 53.26$ & 0.806 & $0.998(0.986-1.010)$ \\
\hline Triglycerides (mg/dl) & $114.32 \pm 59.26$ & $116.31 \pm 56.76$ & 0.900 & $1.001(0.992-1.009)$ \\
\hline HDL cholesterol (mg/dl) & $53.57 \pm 11.63$ & $54.50 \pm 15.96$ & 0.826 & $1.006(0.964-1.050)$ \\
\hline LDL cholesterol (mg/dl) & $119.92 \pm 41.81$ & $124.44 \pm 49.93$ & 0.734 & $1.002(0.990-1.015)$ \\
\hline Serum insulin (ulU/ml) & $9.349 \pm 6.129$ & $13.745 \pm 7.664$ & $0.002^{*}$ & $1.119(1.042-1.201)$ \\
\hline HOMA-IR & $2.100 \pm 1.386$ & $4.564 \pm 4.301$ & $0.000^{\star}$ & 1.605 (1.249-2.062) \\
\hline C-reactive protein $(\mathrm{mg} / \mathrm{dl})$ & $1.04 \pm 1.68$ & $2.25 \pm 5.38$ & $0.025^{*}$ & $1.136(1.165-1.336)$ \\
\hline $\mathrm{ESR}(\mathrm{mm} / \mathrm{h})$ & $36.99 \pm 24.62$ & $37.00 \pm 24.71$ & 0.999 & $1(0.979-1.022)$ \\
\hline RF positive & 77 (71.30) & $14(87.5)$ & $0.017^{*}$ & $0.264(0.089-0.787)$ \\
\hline ACCP antibody positive & $75(69.44)$ & $14(87.5)$ & $0.048^{*}$ & $4.631(1.002-21.40)$ \\
\hline \multicolumn{5}{|l|}{ ACCP antibody level } \\
\hline Low positive & $43(39.81)$ & $4(25)$ & $0.012^{*}$ & $2.589(1.238-5.415)$ \\
\hline Strong positive & $32(29.63)$ & $10(62.5)$ & & \\
\hline \multicolumn{5}{|l|}{ Radiological parameters } \\
\hline CIMT (mm) & $0.68 \pm 0.16$ & $0.81 \pm 0.15$ & $0.006^{\star}$ & $109.6(3.8-3136.13)$ \\
\hline Plaques positive & $17(15.74)$ & $10(62.5)$ & $0.034^{*}$ & $0.313(0.107-0.915)$ \\
\hline
\end{tabular}

Values are given as mean \pm SD or $n(\%)$. ACCP, anticyclic citrullinated protein antibody; ACS, acute coronary syndrome; CVR, cardiovascular risk; DAS28, disease activity score 28; ESR, erythrocyte sedimentation rate; EULAR, European League against Rheumatism; HAQ, Health Assessment Questionnaire; HDL, high-density lipoprotein; HOMA-IR, homeostasis model assessment-insulin resistance; $\mathrm{Cl}$, confidence interval; CIMT, carotid intima-media thickness; LDL, low-density lipoprotein; RA, rheumatoid arthritis; RF, rheumatoid factor. ${ }^{a}$ Systolic pressure $>150 \mathrm{mmHg}$ or diastolic pressure $>90 \mathrm{mmHg} .{ }^{*} P<0.05 .{ }^{* \star} P<0.001$.

characteristics entered into the model, three $(\mathrm{RF}$, presence of anticyclic citrullinated protein antibodies, and carotid plaques) were significantly associated with ACS.

Pharmacologic therapies used in the treatment of RA patients are presented in Table 3. As expected, among the vast majority of RA patients with and those without ACS under DMARDs treatment, there was no statistically significant difference between the two groups with regard to line of treatment. More than $90 \%$ of patients were under DMARDs and approximately one-third in each group received corticosteroids. No significant difference emerged between the two groups either in antiplatelet usage (aspirin), lipid-lowering agent (statin), cumulative steroid dose, anti-tumor necrosis factor (anti-TNF) therapy (adalimumab, etanrecept, and infliximab), interleukins-6 receptors inhibitor (tocilizumab), abatacept, and rituximab.

\section{Discussion}

The focus of this study was to examine factors associated with the presence of ACS in RA patients. Inflammation is a key feature during all stages of atherosclerotic pathogenesis [21]. Inflammation affects the composition and stability of atherosclerotic lesions 
and also promotes clotting [22], and hence induces permissive conditions for atherothrombotic events. Our findings of an association between indices of high average clinical disease activity, based on DAS28, patient global health assessment questioner score, and the risk for ACS is consistent with previous reports [2,23,24].

High inflammatory activity worsens clinical symptoms and general well-being, leading to poorer general health, and hence DAS28 score. High overall disease activity reduces the level of physical function. Furthermore, implementation of adequate physical

\section{Figure 1}

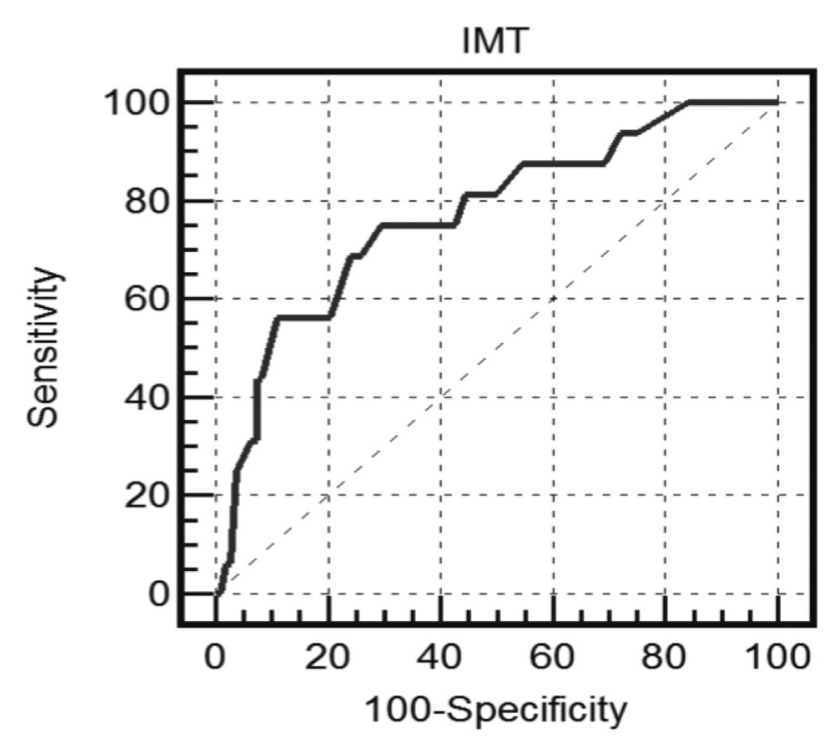

Receiver operating characteristic (ROC) curves between acute coronary syndrome outcome (positive and negative) and carotid intimamedia thickness. activity levels has been associated with a better CV profile in RA [25]. Importantly, the general health score does not reflect merely RA disease activity but can also be affected by the presence of other comorbidities and by general well-being. We also documented a positive association between ACS and RA disease duration. This suggests a role for chronic inflammation in the development of $\mathrm{CV}$ event.

The increased risk for CVD in RA is associated with, although not entirely attributed to, traditional risk factors already established in the general population [9]. Similarly, we found that there was no association between hypertension, diabetes mellitus, or smoking as independent parameters and ACS. Even diabetes and hypertension remained independently associated with ACS that served to refocus attention on their importance in determining the existence of $\mathrm{CV}$ events in RA.

Ljung et al. [26] documented that the risk for ischemic heart disease in patients with RA was elevated compared with general population and was less manifest in TNF-exposed patients. This risk has been linked to the degree of activity and severity of the disease.

Patients with high BMI and high 10-year CVD risk score were significantly associated with a risk for ACS. In recent years, there has been an increased appreciation that adipose tissue should be viewed as an active endocrine organ. Adipocytokines, in particular adiponectin, are known to have antidiabetic, insulin sensitizing, anti-inflammatory,

Table 2 Multivariable logistic regression model for acute coronary syndrome

\begin{tabular}{|c|c|c|c|c|c|c|c|}
\hline & \multirow[t]{2}{*}{$B$} & \multirow[t]{2}{*}{ SE } & \multirow[t]{2}{*}{ Wald } & \multirow[t]{2}{*}{$P$-value } & \multirow[t]{2}{*}{ Odd } & \multicolumn{2}{|c|}{$95 \% \mathrm{Cl}$ for odd } \\
\hline & & & & & & Lower & Upper \\
\hline Age (years) & 0.117 & 0.111 & 1.125 & 0.289 & 1.124 & 0.905 & 1.396 \\
\hline BMI $\left(\mathrm{kg} / \mathrm{m}^{2}\right)$ & 0.198 & 0.128 & 2.379 & 0.123 & 1.219 & 0.948 & 1.567 \\
\hline Duration (years) & 0.417 & 0.237 & 3.093 & 0.079 & 1.518 & 0.953 & 2.417 \\
\hline DAS28 & 0.574 & 0.794 & 0.523 & 0.470 & 1.776 & 0.374 & 8.424 \\
\hline $\mathrm{HAQ}$ & -0.017 & 0.049 & 0.126 & 0.723 & 0.983 & 0.893 & 1.082 \\
\hline Serum insulin $(\mu \mathrm{lU} / \mathrm{ml})$ & -0.013 & 0.133 & 0.010 & 0.922 & 0.987 & 0.761 & 1.281 \\
\hline HOMA-IR & 0.751 & 0.442 & 2.888 & 0.089 & 2.120 & 0.891 & 5.041 \\
\hline RF Positivity & -9.472 & 3.870 & 5.990 & $0.014^{\star}$ & 0.000 & 0.000 & 0.152 \\
\hline ACCP Positivity & 11.713 & 5.088 & 5.299 & $0.021^{*}$ & 122139.153 & 5.701 & 2616927866.53 \\
\hline ACCP level & -0.708 & 1.329 & 0.283 & 0.594 & 0.493 & 0.036 & 6.670 \\
\hline 10 years CVR & 0.160 & 0.190 & 0.711 & 0.399 & 1.174 & 0.809 & 1.703 \\
\hline C-reactive protein (mg/dl) & 0.200 & 0.160 & 1.564 & 0.211 & 1.221 & 0.893 & 1.670 \\
\hline CIMT (mm) & -3.571 & 7.531 & 0.225 & 0.635 & 0.028 & 0.000 & 72376.604 \\
\hline Plaques & 1.967 & 0.702 & 7.854 & $0.005^{*}$ & 7.150 & 1.807 & 28.299 \\
\hline
\end{tabular}

ACCP, anticyclic citrullinated protein antibody; B, coefficient; CIMT, carotid intima-media thickness; CVR, cardiovascular risk; DAS28, disease activity score 28; HAQ, Health Assessment Questionnaire; HOMA-IR, homeostasis model assessment-insulin resistance; OR, odds ratio; RF, rheumatoid factor. ${ }^{\star} P<0.05$. ${ }^{\star *} P<0.001$. 
Table 3 Comparisons between two groups as regards line of treatment

\begin{tabular}{|c|c|c|c|c|}
\hline & Patients without ACS $(n=108)[n(\%)]$ & Patients with ACS $(n=16)[n(\%)]$ & $P$-value & Odd $(95 \% \mathrm{Cl})$ \\
\hline \multicolumn{5}{|l|}{ Line of treatment } \\
\hline Statin usage & $50(46.30)$ & $11(68.75)$ & 0.094 & $3.353(1.017-11.05) 4$ \\
\hline Asprin usage & $51(47.22)$ & $11(68.75)$ & 0.179 & $0.4067(0.132-1.249)$ \\
\hline \multicolumn{5}{|l|}{ DMARDs } \\
\hline MTX & $99(91.67)$ & $15(93.75)$ & 0.768 & $1.364(0.161-11.546)$ \\
\hline Other than MTX & $98(90.74)$ & $16(100.00)$ & 0.999 & - \\
\hline Corticosteroid & $42(38.89)$ & $5(31.25)$ & 0.557 & $0.714(0.232-2.202)$ \\
\hline Corticosteroid dose $(\mathrm{mg})$ & $2.07 \pm 2.75$ & $1.56 \pm 2.39$ & 0.447 & $0.928(0.752-1.145)$ \\
\hline \multicolumn{5}{|l|}{ bDMARDs } \\
\hline Adalimumab & $12(11.11)$ & $1(6.25)$ & 0.662 & $0.776(0.372-1.621)$ \\
\hline Etanrecept & $13(12.04)$ & $2(12.50)$ & & \\
\hline Infleximab & $4(3.70)$ & $0(0.00)$ & & \\
\hline Tocilizumab & $14(12.96)$ & $1(6.25)$ & 0.453 & $0.448(0.055-3.658)$ \\
\hline Abatacebt & $14(12.96)$ & $4(25)$ & 0.211 & $2.238(0.633-7.916)$ \\
\hline Rutoximab & $2(1.85)$ & $0(0.00)$ & 0.455 & - \\
\hline
\end{tabular}

ACS, acute coronary syndrome; bDMARDs, biologic disease-modifying antirheumatic drugs; DMARDs, disease-modifying antirheumatic drugs; MTX, methotrxate.

and vasculature protective properties [25]. Circulating adiponectin reduced with increasing adiposity (BMI), IR, atherogenic lipid profile, increased inflammatory markers (CRP, TNF, and interleukin-6), which lead to increased risk for CVD and possibly coronary plaque susceptibility [27-30].

In this study, no significant difference in the lipid profile was found between the RA patients with and those without ACS. In RA, inflammation is associated with a paradoxical inversion of the relationship between CV risk and lipid levels [31-33]. Importantly, several studies have reported increases in lipid levels with a successful reduction in RA disease activity following anti-inflammatory treatment [34]. These findings suggest that the traditional analysis of lipid profiles for predicting $\mathrm{CV}$ risk may be confused with disease activity in RA patients $[31,32]$.

In the present study, IR determined using the HOMA-IR was found to be significantly higher in the ACS patient group compared with the non-ACS group. Our results as well as those obtained from La Montagna et al. [17] revealed a significant difference between the two groups as regards HOMA-IR.

In our study, RF and ACPA positivity were associated with an increased risk for ACS. Seropositivity, for either RF or ACPAs, is associated with a more severe clinical prognosis $[35,36]$. Studies that have identified $\mathrm{RF}$ as a risk factor for $\mathrm{CVD}$ in $\mathrm{RA}$ are typically based on older cohorts [37-39], whereas one study of a contemporary RA cohort failed to identify $\mathrm{RF}$ as a CV risk marker [24]. It is possible that the development of more efficient RA treatments has effectively altered and improved the disease course of patients who otherwise would have had more severe disease, and that previously reported associations were a reflection of severe disease. In a Spanish RA cohort enrolled between 1988 and 2003, the presence of ACPA was associated with a 2.5 -fold increased risk for ischemic heart disease even after adjustment for erythrocyte sedimentation rate, $\mathrm{RF}$, and treatments [24]. ACPA-positive RA has also been associated with an increased risk for subclinical manifestations of CVD, such as more extensive atherosclerotic lesions and structural myocardial abnormalities [40].

There was a strong confirmation suggesting that chronic inflammation plays a role in atherogenesis and in CV morbidity and mortality [41-44].

In addition to the high-grade inflammation seen in rheumatoid joints, blood from RA patients also demonstrate a high concentration of markers of inflammation, such as interleukin-1 and TNF- $\alpha$ [45].

These markers regulate cell-mediated immunity, promoting inflammatory cell migration through the vascular endothelium, resulting in endothelial dysfunction $[46,47]$.

The CIMT has been linked with the severity and the chronicity of the inflammatory response. Longstanding RA patients with mean CRP levels greater than $15 \mathrm{mg} / \mathrm{dl}$ had higher CIMT values than those with lower CRP levels [48]. In agreement with the previous reports [46-49], our findings suggest that atherosclerosis is a good predictor for the $\mathrm{CV}$ complications of RA patients. At a cutoff value of 
CIMT greater than or equal to $0.72 \mathrm{~mm}$, the sensitivity and specificity were 75.0 and $70.4 \%$, respectively, with an accuracy of $76.9 \%$ in the prediction of ACS. The presence of plaque in both internal carotid arteries nearly quadrupled the incidence of new ACS compared with that in patients without carotid plaque. Logistic regression analysis showed that plaques were a good predictor for ACS in RA patients. In the multivariable logistic regression model the presence of carotid plaques remained a strong predictor for ACS. The absence of the residual variables from the predictive model should not be understood to mean that they are not associated with ACS, but rather that more outcome events (i.e. more statistical power) would be needed to detect their weaker signals. Alternatively, their absence from the predictive model could mean that their association with ACS is mediated through atherosclerosis. An example of the latter is shown in Table 3, in which age loses its association with ACS, suggesting that age is associated with ACS through the mechanism of atherosclerosis accrual over time.

Further longitudinal follow-up of these patients over a period of time to look for clinical events that reflect the consequences of atherosclerosis would provide valuable corroboration of the observations from this study. Furthermore, the present study was conducted in a Saudi RA population, reflecting only the Saudi healthcare setting. Studying of ACS risk factors should be generalizable; the observed risks may not be directly applicable to populations with different levels of disease control, other CV risk factors, or underlying ACS risks.

\section{Conclusion}

The main finding of this study was a general tendency toward an association between disease activity, RF, and ACPA with the risk for ACS. In addition, subclinical atherosclerosis detected by CIMT and the presence of carotid plaques were good predictors for RA patients with ACS. Treatment with methotrexate or any other DMARD, biologic DMARDs, was not linked to an altered risk of ACS in the time frames under study.

\section{Financial support and sponsorship}

Nil.

\section{Conflicts of interest}

There are no conflicts of interest.

\section{References}

1 Aviña-Zubieta JA, Choi HK, Sadatsafavi M, Etminan M, Esdaile JM, Lacaille D. Risk of cardiovascular mortality in patients with rheumatoid arthritis: a meta-analysis of observational studies. Arthritis Rheum 2008; 59: 1690-1697.

2 Meune C, Touze E, Trinquart L, Allanore Y. Trends in cardiovascular mortality in patients with rheumatoid arthritis over 50 years: a systematic review and meta-analysis of cohort studies. Rheumatology 2009; 48: 1309-1313.

3 Gullick NJ, Scott DL. Co-morbidities in established rheumatoid arthritis. Best Pract Res Clin Rheumatol 2011; 25:469-483.

4 Gabriel SE. Cardiovascular morbidity and mortality in rheumatoid arthritis. Am J Med 2008; 121(Suppl 1): S9-S14.

5 Gonzalez A, Maradit Kremers H, Crowson CS, Ballman KV, Roger VL, Jacobsen SJ, et al. Do cardiovascular risk factors confer the same risk for cardiovascular outcomes in rheumatoid arthritis patients as in nonrheumatoid arthritis patients? Ann Rheum Dis 2008; 67:64-69.

6 Boyer JF, Gourraud PA, Cantagrel A, Davignon JL, Constantin A. Traditional cardiovascular risk factors in rheumatoid arthritis: a metaanalysis. Joint Bone Spine 2011; 78:179-183.

7 Dessein PH, Joffe BI, Veller MG, Stevens BA, Tobias M, Reddi K, et al. Traditional and nontraditional cardiovascular risk factors are associated with atherosclerosis in rheumatoid arthritis. J Rheumatol 2005; 32 : 435-442.

8 Ku IA, Imboden JB, Hsue PY, Ganz P. Rheumatoid arthritis: model of systemic inflammation driving atherosclerosis. Circ J 2009; 73:977-985.

9 Del Rincon ID, Williams K, Stern MP, Freeman GL, Escalante A. High incidence of cardiovascular events in a rheumatoid arthritis cohort not explained by traditional cardiac risk factors. Arthritis Rheum 2001; 44:2737-2745.

10 Aletaha D, Neogi T, Silman AJ, Funovits J, Felson DT, Bingham CO 3rd, et al. 2010 rheumatoid arthritis classification criteria: an American College of Rheumatology /European League Against Rheumatism collaborative initiative. Ann Rheum Dis 2010; 69:1580-1588.

11 Prevoo ML, Van't Hof MA, Kuper HH, van Leeuwen MA, van de Putte LB, van Riel PL. Modified disease activity scores that include twenty-eight-joint counts. Development and validation in a prospective longitudinal study of patients with rheumatoid arthritis. Arthritis Rheum 1995;38:44-48.

12 Aletaha D, Smolen J. Disease activity index (CDAl) a review of their usefulness and validity. The simplified disease activity index (SDAI) and the clinical in rheumatoid arthritis. Clin Exp Rheumatol 2005; 23: S100-S108.

13 Pincus T, Summey JA, Soraci SA Jr, Wallston KA, Hummon NP. Assessment of patient satisfaction in activities of daily living using a modified Stanford Health Assessment Questionnaire. Arthritis Rheum 1983; 26:1346-1353.

14 Alpert JS, Thygesen K, Antman E, Bassand JP. Myocardial infarction redefined - a consensus document of The Joint European Society of Cardiology/American College of Cardiology Committee for the redefinition of myocardial infarction. J Am Coll Cardiol 2000; 36:959-969

15 Peters MJL, Symmons DPM, McCarey D, Dijkmans BAC, Nicola P, Kvien TK, et al. EULAR evidence-based recommendations for cardiovascular risk management in patients with rheumatoid arthritis and other forms of inflammatory arthritis. Ann Rheum Dis 2010; 69:325-331.

16 Wallace TM, Levy JC, Mattews D. Use and abuse of HOMA modelling. Diabetes Care 2004; 27:1487-1495.

17 La Montagna G, Cacciapuoti F, Buono R, Manzella D, Mennillo GA, Arciello $A$, et al. Insulin resistance is an independent risk factor for atherosclerosis in rheumatoid arthritis. Diab Vasc Dis Res 2007; 4:130-135.

18 Corrales A, Gonzalez-Juanatey C, Peiro ME, Blanco R, Llorca J, GonzálezGay MA. Carotid ultrasound is useful for the cardiovascular risk stratification of patients with rheumatoid arthritis: results of a populationbased study. Ann Rheum Dis 2014; 73:722-727.

19 Homma S, Hirose N, Ishida H, Ishii T, Araki G. Carotid plaque and intimamedia thickness assessed by $\mathrm{b}$-mode ultrasonography in subjects ranging from young adults to centenarians. Stroke 2001; 32:830-835.

20 Touboul PJ, Hennerici MG, Meairs S, Adams H, Amarenco P, Bornstein N, et al. Mannheim carotid intima-media thickness consensus (2004-2006). An update on behalf of the Advisory Board of the 3rd and 4th Watching the Risk Symposium, 13th and 15th European Stroke Conferences, Mannheim, Germany, 2004, and Brussels, Belgium, 2006. Cerebrovasc Dis 2007; 23:75-80.

21 Libby P. Inflammation in atherosclerosis. Arterioscler Thromb Vasc Biol 2012; 32:2045-2051. 
22 Libby P. Role of inflammation in atherosclerosis associated with rheumatoid arthritis. Am J Med 2008; 121(Suppl 1):S21-S31.

23 Ajeganova S, Andersson ML, Frostegard J, Hafstrom I. Disease factors in early rheumatoid arthritis are associated with differential risks for cardiovascular events and mortality depending on age at onset: a 10year observational cohort study. J Rheumatol 2013; 40:1958-1966.

24 Innala L, Moller B, Ljung L, Magnusson S, Smedby T, Södergren A, et al. Cardiovascular events in early RA are a result of inflammatory burden and traditional risk factors: a five year prospective study. Arthritis Res Ther 2011; 13:R131.

25 Stavropoulos-Kalinoglou A, Metsios GS, Veldhuijzen van Zanten JJ, Nightingale P, Kitas GD, Koutedakis Y. Individualised aerobic and resistance exercise training improves cardiorespiratory fitness and reduces cardiovascular risk in patients with rheumatoid arthritis. Ann Rheum Dis 2013; 72:1819-1825.

26 Ljung L, Askling J, Rantapää-Dahlqvist S, Jacobsson L ARTIS Study Group. The risk of acute coronary syndrome in rheumatoid arthritis in relation to tumor necrosis factor inhibitors and the risk in the general population: a national cohort study. Arthritis Res Ther 2014; 16:R127.

27 Santos MJ, Fonseca JE. Metabolic syndrome, inflammation and atherosclerosis - the role of adipokines in health and in systemic inflammatory rheumatic diseases. Acta Reumatol Port 2009; 34:590-598.

28 Lee SH, Ha JW, Kim JS, Choi EY, Park S, Kang SM, et al. Plasma adiponectin and resistin levels as predictors of mortality in patients with acute myocardial infarction: data from infarction prognosis study registry. Coron Artery Dis 2009; 20:33-39.

29 Kumada M, Kihara S, Sumitsuji S, Kawamoto T, Matsumoto S, Ouchi N, et al. Association of hypoadiponectinemia with coronary artery disease in men. Arterioscler Thromb Vasc Biol 2003; 23:85-89.

30 Broedl UC, Lebherz C, Lehrke M, Stark R, Greif M, Becker A, et al. Low adiponectin levels are an independent predictor of mixed and non-calcified coronary atherosclerotic plaques. PLoS One 2009; 4:e4733.

31 Myasoedova E, Crowson CS, Kremers HM, Roger VL, Fitz-Gibbon PD, Therneau TM, et al. Lipid paradox in rheumatoid arthritis: the impact of serum lipid measures and systemic inflammation on the risk of cardiovascular disease. Ann Rheum Dis 2011; 70:482-487.

32 Choy E, Sattar N. Interpreting lipid levels in the context of high-grade inflammatory states with a focus on rheumatoid arthritis: a challenge to conventional cardiovascular risk actions. Ann Rheum Dis 2009; 68:460-469.

33 Robertson J, Peters MJ, Mclnnes IB, Sattar N. Changes in lipid levels with inflammation and therapy in RA: a maturing paradigm. Nat Rev Rheumatol 2013; 9:513-523.

34 Daïen $\mathrm{Cl}$, Duny Y, Barnetche T, Daurès JP, Combe B, Morel J. Effect of TNF inhibitors on lipid profile in rheumatoid arthritis: a systematic review with meta-analysis. Ann Rheum Dis 2012; 71:862-868.
35 Vencovsky J, Machacek S, Sedova L, Kafkova J, Gatterova J, Pesáková V, et al. Autoantibodies can be prognostic markers of an erosive disease in early rheumatoid arthritis. Ann Rheum Dis 2003; 62:427-430.

36 Kroot EJ, de Jong BA, van Leeuwen MA, Swinkels H, van den Hoogen FH, van't Hof M, et al. The prognostic value of anti-cyclic citrullinated peptide antibody in patients with recent-onset rheumatoid arthritis. Arthritis Rheum 2000; 43:1831-1835.

37 Maradit-Kremers H, Nicola PJ, Crowson CS, Ballman KV, Gabriel SE. Cardiovascular death in rheumatoid arthritis: a population-based study. Arthritis Rheum 2005; 52:722-732.

38 Wallberg-Jonsson S, Johansson $\mathrm{H}$, Ohman ML, Rantapaa-Dahlqvist S. Extent of inflammation predicts cardiovascular disease and overall mortality in seropositive rheumatoid arthritis: a retrospective cohort study from disease onset. J Rheumatol 1999; 26:2562-2571.

39 Gonzalez A, Icen M, Kremers HM, Crowson CS, Davis JM 3rd, Therneau $\mathrm{TM}$, et al. Mortality trends in rheumatoid arthritis: the role of rheumatoid factor. J Rheumatol 2008; 35:1009-1014.

40 López-Longo FJ, Oliver-Miñarro D, de la Torre I, González-Daíz de Rábago E, Sánchez-Ramón S, Rodríguez-Mahou $\mathrm{M}$, et al. Association between anti-cyclic citrullinated peptide antibodies and ischemic heart disease in patients with rheumatoid arthritis. Arthritis Rheum 2009; 61 419-424.

41 Pasceri V, Yeh ET. A tale of two diseases: atherosclerosis and rheumatoid arthritis. Circulation 1999; 100:2124-2126.

42 Ridker PM, Cushman M, Stampfer MJ, Tracy RP, Hennekens $\mathrm{CH}$. Inflammation, aspirin, and the risk of cardiovascular disease in apparently healthy men. N Engl J Med 1997; 336:973-979.

43 Danesh J, Collins R, Peto R. Chronic infections and coronary heart disease: is there a link? Lancet 1997; 350:430-436

44 Van Doornum S, McNoll G, Wicks IP. Accelerated atherosclerosis: an extra-articular feature of rheumatoid arthritis? [review]. Arthritis Rheum 2002; 46:862-873.

45 Willerson JT, Ridker PM. Inflammation as a cardiovascular risk factor Circulation 2004; 109:II-2-II-10.

46 Agewall S. Is impaired flow-mediated dilation of the brachial artery a cardiovascular risk factor? Curr Vasc Pharmacol 2003; 1:107-109.

47 Vita JA, Keaney JF. Endothelial function: a barometer for cardiovascular risk? Circulation 2002; 196:640-642.

48 Gonzalez-Gay MA, Gonzalez-Juanatey C, Piñeiro A, Garcia-Porrua C, Testa A, Llorca J. High-grade C-reactive protein elevation correlates with accelerated atherogenesis in patients with rheumatoid arthritis. Rheumatol 2005; 132:1219-1223.

49 Evans MR, Escalante A, Battafarano DF, Freeman GL, O'Leary DH, de Rincón I. Carotid atherosclerosis predicts incident acute coronary syndromes in rheumatoid arthritis. Arthritis Rheum 2011; 63:1211-1220. 